\title{
SELEÇÃO DE CLONES DE BATATA-DOCE RESISTENTES A INSETOS DE SOLO'
}

\author{
JOSÉ RICARDO PEIXOTO², LUCIANA CRISTINA SANTOS ${ }^{3}$, FABRICIO DE ÁVILA RODRIGUES ${ }^{4}$, \\ FERNANDO CESAR JULIATTI ${ }^{5}$ e JAIRO ROBERTO MENDONÇA LYRA ${ }^{6}$
}

\begin{abstract}
RESUMO - O objetivo deste trabalho foi selecionar clones comerciais de batata-doce para a região do Triângulo Mineiro. Dos clones avaliados, 60 foram obtidos por policruzamentos e cedidos pela Universidade Federal de Lavras (UFLA), três, entre produtores rurais dos municípios de Araguari, Uberlândia e Machado, todos do Estado de Minas Gerais, e outros nove foram usados como testemunhas (Brazlândia Branca, Brazlândia Rosada, Surpresa, Rio Doce, Morena Roxa, Coquinho, Arroba, Pira 1 e o Clone 042). O experimento foi instalado no espaçamento de 1,10 x 0,45 m, utilizando-se o delineamento blocos casualizados, com 72 tratamentos, quatro repetições e 16 plantas por parcela. Entre os clones avaliados 32,8\% apresentaram alta ou moderada resistência a insetos de solo. O clone 95041 foi o mais produtivo, com 28.048,96 kg/ha. Os clones 95009, 95010, 95014, 95020, 95033, 95042 e 95057 foram altamente resistentes a insetos de solo.
\end{abstract}

Termos para indexação: Ipomoea batatas, melhoramento, resistência.

\section{SCREENING OF SWEET POTATO CLONES RESISTANT TO SOIL INSECTS}

\begin{abstract}
A research was carried out with the objective of selecting commercial clones for weather conditions of the Triângulo Mineiro, Minas Gerais State, Brazil. Sixty of the clones evaluated were obtained by polycross and given by the Universidade Federal de Lavras, three were from the farmers of the municipalities of Araguari, Uberlândia and Machado, located in Minas Gerais State, and nine clones were used as standards (Brazlândia Branca, Brazlândia Rosada, Surpresa, Rio Doce, Morena Roxa, Coquinho, Arroba, Pira 1 and Clone 042). The experiment was installed in a spacing of $1.10 \times 0.45 \mathrm{~m}$, using a randomized block design, with 72 treatments, four replicates and 16 plants per plot. Among the evaluated clones, $32.8 \%$ showed high or moderate resistance to soil insects. The clone with the highest yield was the clone number 95041, which produced 28,048.96 kg/ha. The others, $95009,95010,95014,95020,95033,95042$ and 95057 were highly resistant to soil insects.
\end{abstract}

Index terms: Ipomoea batatas, breeding, resistance.

${ }^{1}$ Aceito para publicação em 16 de julho de 1998.

Apoio financeiro da FUNDAP - Fundação de Desenvolvimento Agropecuário/UFU.

${ }^{2}$ Eng. Agr., Dr., Faculdade de Agronomia e Med. Veterinária, UnB, Caixa Postal 04.508, CEP 70910-900 Brasília, DF. E-mail: peixoto@guarany.unb.br

${ }^{3}$ Estudante, Dep.de Agronomia (DEAGO), Universidade Federal de Uberlândia (UFU), Caixa Postal 593, CEP 38400-902 Uberlândia, MG.

${ }^{4}$ Eng. Agr., Rua 3 de Abril, 99, Bairro Amorin, CEP 38440-000 Araguari, MG.

${ }^{5}$ Eng. Agr., Dr., DEAGO, UfU.

${ }^{6}$ Eng. Agr., Dr., DEAGO, UFU. Bolsista do CNPq.

\section{INTRODUÇÃO}

A batata-doce (Ipomoea batatas (L.) Lamarckd) é uma cultura pouco exigente em fertilidade do solo, de fácil cultivo, ampla adaptação, alta tolerância à seca e baixo custo de produção (Miranda et al., 1987). É uma das plantas de raiz tuberosa mais cultivada pelo homem nas regiões tropicais e subtropicais, e seu cultivo se destina às mais diversas formas de utilização, desde a dieta humana até a indústria de álcool e derivados. Com uma área aproximada de plantio de 82.000 ha e produtividade 
média de $8,9 \mathrm{t} / \mathrm{ha}$, o Brasil ocupa atualmente o décimo lugar, na produção dessa cultura. Entretanto, no início da década de 60 , a área plantada era de aproximadamente 180.000 ha. Assim, verifica-se que tal cultura vem experimentando, nos últimos anos, uma fase de plena decadência na área de plantio, além de uma perda média de produtividade de 2 t/ha no período (Miranda et al., 1987; Guedes, 1988).

Apesar de ser bastante rústica, a batata-doce é susceptível a um grande número de doenças causadas por fungos, vírus, nematóides bem como ao ataque de numerosas pragas, insetos e ácaros (Huang et al., 1986; Jones et al., 1986; Maluf et al., 1987; Miranda et al., 1987).

A utilização de inseticidas de solo na cultura da batata-doce não tem sido recomendada como prática, por ser ineficiente e antieconômica (Miranda et al., 1987). Contudo, a utilização de germoplasmas de batata-doce resistentes a insetos de solo tem sido possível, constituindo-se numa importante alternativa de controle (Jones et al., 1986). O Brasil possui um vasto germoplasma mantido por pequenos agricultores, comunidades indígenas e até mesmo em hortas domésticas. Por isso é necessário que o maior número de introduções de batata-doce seja testado mediante técnicas eficazes e rápidas, para a identificação de clones resistentes aos insetos do solo (Silveira, 1993).

O presente trabalho teve os seguintes objetivos: avaliar uma coleção de clones de batata-doce recombinados por policruzamentos, além de outros coletados entre produtores rurais, quanto à produtividade, qualidade e resistência aos insetos de solo; fazer seleção de clones resistentes aos insetos de solo e mais produtivos, para posterior policruzamento.

\section{MATERIAL E MÉTODOS}

O experimento foi conduzido em solo do tipo Latossolo Vermelho-Escuro, com textura argilosa, na Fazenda Capim Branco, da Universidade Federal de Uberlândia (UFU), MG.

Foi efetuada uma primeira aração profunda $(25 \mathrm{~cm})$, para maior revolvimento do solo e dos restos culturais. Depois de 60 dias, aproximadamente, foi efetuada nova aração seguida de gradagem. Os camalhões foram feitos com $0,40 \mathrm{~m}$ de altura e no espaçamento de $1,10 \mathrm{~m}$ entre eles. Foi aplicada, em sulcos, a adubação de plantio, cuja dosagem foi calculada mediante análise de solo (Tabela 1), seguindo as recomendações da Comissão de Fertilidade do Solo do Estado de Minas Gerais (1989).

Foram utilizados 60 clones obtidos por policruzamentos e cedidos pelo Setor de Olericultura da Universidade Federal de Lavras (UFLA), três provenientes de produtores rurais de municípios de Minas Gerais (Araguari, Uberlândia e Machado) e mais nove testemunhas: Brazlândia Branca, Brazlândia Rosada, Surpresa, Morena Roxa, Rio Doce, Arroba, Coquinho, Clone 042 e Pira 1, esta última resistente a insetos de solo.

Foi utilizado o delineamento experimental de blocos casualizados, com 72 tratamentos e quatro repetições, totalizando 288 parcelas, sendo 16 plantas/parcela e espaçamento de $1,10 \mathrm{~m}$ entre camalhões por $0,45 \mathrm{~m}$ entre plantas. Foram utilizadas bordaduras nas laterais do experimento. No plantio utilizaram-se partes do caule (estaca) da batata-doce com aproximadamente seis gemas, das quais três foram enterradas no solo.

TABELA 1. Análise química e física do solo. UFU, Uberlândia, MG, 1996.

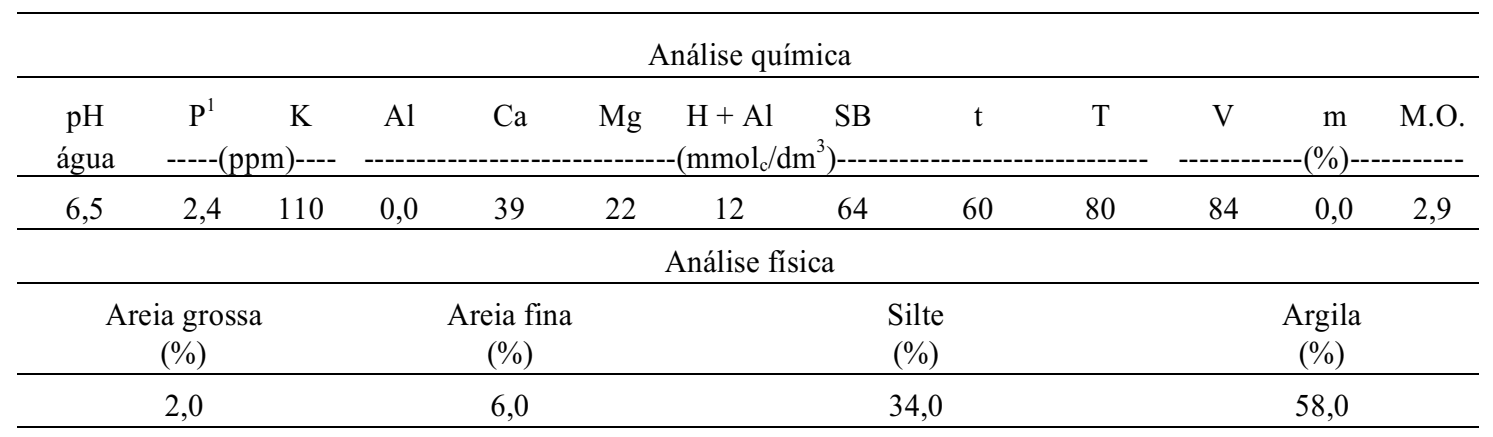

${ }^{1}$ Melich 1. 
Após seis meses do plantio procedeu-se às avaliações. A incidência de danos causados por insetos foi medida segundo a escala de notas estabelecida por França (1995). Foram atribuídas notas por dois avaliadores para danos causados por insetos de solo, numa escala variável de 1 a 5 , na qual a nota 1 correspondeu às raízes livres de danos causados por insetos e de aspecto comercial desejável; a nota 2 , à raiz com poucos e quase imperceptíveis danos, mas que já perde um pouco quanto ao aspecto comercial; a nota 3 foi atribuída àquelas com danos verificados sem muito esforço visual, conseqüentemente com aspecto comercial prejudicado; as de nota 4 foram as que apresentaram danos muito claros, que tornaram a batata praticamente imprestável para comercialização; a nota 5 atribuída às inaceitáveis para fins comerciais e, às vezes, ao consumo humano ou até mesmo ao de animais. Para seleção de genótipos consideram-se como clones resistentes aqueles com notas 1 e 2; moderadamente resistentes, com nota 3; e suscetíveis, com notas 4 e 5 .

Quanto ao formato também foram atribuídas notas entre 1 e 5 , sendo a nota 1 correspondente àquele ideal para batata-doce, ou seja fusiforme regular e sem veias ou qualquer tipo de rachadura; a nota 2 , considerado bom, foi atribuída àquele formato com algumas características indesejáveis como presença de veias ou apresentando-se ligeiramente desuniforme; a nota 3 foi para raízes desuniformes, com veias e rachaduras, bastante irregulares e grandes; a nota 4 foi atribuída a raízes indesejáveis do ponto de vista comercial, por apresentarem-se muito grandes, com rachaduras e presença de veias; a nota 5 foi dada às raízes totalmente fora dos padrões comercialmente desejados, com veias, rachaduras e muito irregulares.

A atribuição de notas para insetos de solo e formato de raiz foi feita escolhendo-se ao acaso doze batatas comerciais por parcela.

A produtividade foi calculada após a pesagem de todas as raízes da parcela, em balança de precisão. O peso total de cada parcela foi extrapolado para $\mathrm{kg} / \mathrm{ha}$.

As análises empregadas na avaliação dos resultados foram baseadas em modelos apropriados para o delineamento utilizado, de acordo com Pimentel-Gomes (1976). Todos os dados foram submetidos à análise de variância utilizando-se para o teste de $\mathrm{F}$ os níveis de $5 \%$ e $1 \%$ de probabilidade. As médias foram comparadas entre si, pelo teste de Tukey, a 5\% de probabilidade.

\section{RESULTADOS E DISCUSSÃO}

Houve diferença significativa entre os tratamentos na análise de resistência mediante as notas $(p<0,01)$. Houve uma grande variação no grau de resistência entre os clones avaliados, dos quais,
$21(32,8 \%)$ foram selecionados por apresentarem alta ou moderada resistência (Tabela 2), especialmente aqueles que tiveram nota inferior a 2,0. Entre as cultivares utilizadas como testemunha, apenas Pira 1 obteve nota inferior aos clones selecionados $(1,58)$, enquanto as demais alcançaram notas entre 2,60 e 3,13 (Tabela 2). Silveira (1993) também verificou a suscetibilidade das cultivares Coquinho e Brazlândia Branca, com notas 3,03 e 3,20, respectivamente, e Azevedo (1995) nas cultivares Brazlândia Rosada, Coquinho e Brazlândia Branca, com notas 2,10, 2,37 e 2,90, respectivamente. Segundo o último autor, as notas mais baixas resultam da baixa incidência de insetos de solo na cultura durante a condução do experimento. Ele acrescenta que essa baixa incidência deve estar relacionada à prática da irrigação, aplicada com freqüência, que pode ter contribuído para a redução dos insetos do solo na cultura. Junqueira \& Saccheta (1964), também observaram que tal prática, além de aumentar consideravelmente a produção e manter as plantas em bom estado, reduziu a infestação da broca-da-raiz (Euscepes postfasciatus).

Houve diferença significativa na produtividade dos genótipos testatos $(\mathrm{p}<0,01)$. Com exceção dos clones 95041 e Machado 1, todos os demais selecionados para resistência foram pouco produtivos (Tabela 2). Entre as cultivares comerciais (testemunhas), duas também foram pouco produtivas (Rio Doce e Coquinho). $\mathrm{O}$ fato de a colheita ter sido efetuada aos seis meses após o plantio prejudicou bastante dezenas de genótipos (clones novos e testemunhas), especialmente aqueles mais sensíveis ao ataque de nematóides e pragas e a distúrbios fisiológicos, que mostraram sintomas típicos de rachadura, na maioria das raízes, depreciando-os para o mercado. Azevedo (1995) verificou uma produção comercial máxima de 29,82 t/ha com o clone 92028 e 28,48 t/ha com Brazlândia Branca, e mínima com os clones 92764 e 92688 , com 1,30 e 1,25 t/ha, respectivamente.

Houve significativa diferença de formato entre os genótipos testados $(\mathrm{p}<0,01)$. Entre os 21 clones selecionados para resistência, todos apresentaram nota de formato inferior a 3,0, variando de 2,0 a 2,93 (Tabela 2), portanto, bastante promissores, especialmente aqueles que mais se aproximaram do formato ideal fusiforme (notas inferiores). As teste- 
TABELA 2. Médias de produtividade comercial e notas de 1 a 5 em danos causados por insetos de solo e em formatos de raízes de 20 clones de batata-doce (Ipomoea batatas (L.) Lam.) selecionados e das nove testemunhas. UFU, Uberlândia, MG, 1996.

\begin{tabular}{|c|c|c|c|}
\hline Clone & $\begin{array}{c}\text { Produtividade comercial } \\
(\mathrm{kg} / \mathrm{ha})\end{array}$ & $\begin{array}{c}\text { Danos causados por insetos } \\
(\text { nota de } 1 \text { a } 5)\end{array}$ & $\begin{array}{l}\text { Formato de raiz } \\
(\text { nota de } 1 \text { a } 5)\end{array}$ \\
\hline 95041 & 28048,06 & 2,20 & 2,48 \\
\hline Machado 1 & 11915,02 & 2,00 & 2,53 \\
\hline 95008 & 6588,67 & 2,10 & 2,93 \\
\hline 95026 & 6280,79 & 2,03 & 2,55 \\
\hline 95009 & 6034,48 & 1,80 & 2,68 \\
\hline 95015 & 5141,63 & 2,18 & 2,83 \\
\hline 95014 & 4187,19 & 1,85 & 2,00 \\
\hline 95010 & 3910,10 & 1,83 & 2,45 \\
\hline 95042 & 2524,63 & 1,80 & 2,70 \\
\hline Clone 042 & 2463,06 & 2,13 & 2,48 \\
\hline 95048 & 2216,75 & 2,13 & 2,20 \\
\hline 95035 & 2032,02 & 2,15 & 2,58 \\
\hline 95050 & 1847,29 & 2,10 & 2,80 \\
\hline 95016 & 1570,20 & 2,05 & 2,33 \\
\hline 95057 & 1329,68 & 1,93 & 2,75 \\
\hline 95033 & 1211,01 & 1,60 & 2,38 \\
\hline 95018 & 1169,95 & 2,03 & 2,60 \\
\hline 95020 & 1016,01 & 1,95 & 2,40 \\
\hline 95024 & 800,49 & 2,08 & 2,55 \\
\hline 95047 & 738,92 & 2,08 & 2,60 \\
\hline 95059 & 738,92 & 2,20 & 2,60 \\
\hline Brazlândia Rosada & 23645,32 & 3,00 & 3,10 \\
\hline Morena Roxa & 17949,51 & 2,85 & 3,18 \\
\hline Pira 1 & 16471,67 & 1,58 & 1,70 \\
\hline Surpresa & 15790,91 & 2,60 & 2,78 \\
\hline Arroba & 12931,04 & 3,10 & 2,80 \\
\hline Brazlândia Branca & 11084,75 & 3,13 & 2,55 \\
\hline Coquinho & 4833,74 & 2,68 & 3,10 \\
\hline Rio Doce & 4125,62 & 2,70 & 2,93 \\
\hline
\end{tabular}

munhas apresentaram em média uma maior nota de formato, variando de 1,7 a 3,18, com sete delas acima de 2,54. Azevedo (1995) também encontrou formato de clones próximos ao ideal, mas também diversos com nota superior a 3,0 . Nas cultivares comerciais o mesmo autor verificou melhor formato em Surpresa, Brazlândia Rosada e Coquinho, com as notas 1,90, 2,57 e 2,93, respectivamente, e pior formato em Brazlândia Branca, com nota 3,00.

Os clones Machado 1 e especialmente 95041 apresentaram, no geral, um bom desempenho, em todos os caracteres avaliados, e foram considerados, portanto, bastante promissores.

\section{CONCLUSÕES}

1. Entre os clones avaliados, 21 apresentam alta ou moderada resistência aos insetos de solo, com destaque para 95009, 95010, 95014, 95020, 95033, 95042 e 95057.

2. O clone 95041 é o mais produtivo entre todos os genótipos testados e apresenta moderada resistência a insetos de solo e formato com regular aceitação comercial . 


\section{REFERÊNCIAS}

AZEVEDO, S.M. de. Avaliação de família de meio-irmãos de batata-doce (Ipomoea batatas $(\mathrm{L}$.) Lam.) quanto a resistência aos nematóides do gênero Meloidogyne e insetos de solo. Lavras: UFLA, 1995. 61p. Tese de Mestrado.

COMISSÃO DE FERTILIDADE DO SOLO DO ESTADO DE MINAS GERAIS. Recomendações para o uso de corretivos e fertilizantes em Minas Gerais: 4a aproximação. Lavras, 1989. 159p.

FRANÇA, F.H. Pragas e seu controle. In: SILVA, J.B.C.; LOPES, C.A.; MIRANDA, J.E.C.; FRANÇA, F.H.; CARRIJO, O.A.; SOUZA, A.F. Cultivo de batatadoce [Ipomoea batatas (L.) Lam.] 3.ed. Brasília: Embrapa-CNPH, 1995. p.14-16. (Embrapa-CNPH. Instruções Técnicas, 70).

GUEDES, A.C. Palestra de abertura. In: FRANÇA, F.H.; LOPES, C.A.; JABUONSKI, R.E. (Eds.). SEMINÁRIO SOBRE A CULTURA DA BATATADOCE. Anais... Brasília: Embrapa-CNPH, 1988. p.7-10.

HUANG, S.P.; MIRANDA, J.E.C.; MALUF, W.R. Resistance to root-knot nematode in a Brazilian sweet potato collection. Fitopatologia Brasileira, Brasília, v.11, p.761-767, 1986.
JONES, A.; DUKES, P.D.; SCHALK, J.M. Sweet potato breeding. In: BASSETT, M.J. (Ed.). Breeding vegetable crops. Eastport: AVI, 1986. p.1-35.

JUNQUEIRA, G.M.; SACCHETA, L.A. A broca da batata-doce Euscepes postifasciatus (Fairmaire) Coleoptera: Curculionidae. O Biológico, São Paulo, v.30, p.53-59, 1964.

MALUF, W.R.; FRANÇA, F.H.; MOURA, W.M.; CASTELO BRANCO, M.; MIRANDA, J.E.C. Screening of sweet potato accessions for resistance to Tetranychus spp. mites. Revista Brasileira de Genética, Ribeirão Preto, v.10, n.3, p.603-610, 1987.

MIRANDA, J.E.C.; FRANÇA, F.H.; CARRIJO, O.A.; SOUZA, A.F. Batata-doce. Brasília: EmbrapaCNPH, 1987. 14p. (Embrapa-CNPH. Circular técnica, 3).

PIMENTEL-GOMES, F. Curso de Estatística Experimental. 6.ed. São Paulo: Nobel, 1976. 430p.

SILVEIRA, M.A. da. Resistência de clones de batatadoce [Ipomoea batatas (L.) Lamarck] quanto aos nematóides do gênero Meloidogyne e aos insetos de solo. Lavras: ESAL, 1993. 41p. Tese de Mestrado. 